\title{
Article \\ On the Potential of Augmented Reality for Mathematics Teaching with the Application cleARmaths
}

\author{
Stefanie Schutera ${ }^{1}$, Marc Schnierle ${ }^{2}$, Mathilde Wu ${ }^{1}$, Tim Pertzel ${ }^{1}$, Jonathan Seybold ${ }^{1}$, Patricia Bauer ${ }^{1}$, \\ Dennis Teutscher $^{1, *}$, Matthias Raedle ${ }^{3}\left(0\right.$, Natascha Heß-Mohr ${ }^{3}$, Sascha Röck ${ }^{2}$ and Mathias J. Krause ${ }^{1} \mathbb{}$ \\ 1 Lattice Boltzmann Research Group, Karlsruhe Institute of Technology, 76131 Karlsruhe, Germany; \\ stefanie.schutera@gmail.com (S.S.); mathilde.wu@kit.edu (M.W.); tim@pertzel.com (T.P.); \\ jonathan.seybold@googlemail.com (J.S.); udysp@student.kit.edu (P.B.); mathias.krause@kit.edu (M.J.K.) \\ 2 Virtual Automation Lab, Esslingen University of Applied Sciences, 73728 Esslingen, Germany; \\ marc.schnierle@hs-esslingen.de (M.S.); sascha.roeck@hs-esslingen.de (S.R.) \\ 3 Center of Mass Spectrometry and Optical Spectroscopy, Mannheim University of Applied Sciences, \\ 68163 Mannheim, Germany; m.raedle@hs-mannheim.de (M.R.); n.hess-mohr@hs-mannheim.de (N.H.-M.) \\ * Correspondence: dennis.teutscher@kit.edu
}

check for updates

Citation: Schutera, S.; Schnierle, M.; Wu, M.; Pertzel, T.; Seybold, J.; Bauer, P.; Teutscher, D.; Raedle, M.; Heß-Mohr, N.; Röck, S.; et al. On the Potential of Augmented Reality for Mathematics Teaching with the Application cleARmaths. Educ. Sci. 2021, 11, 368. https://doi.org/ 10.3390/educsci11080368

Academic Editor: Su Cai

Received: 17 May 2021

Accepted: 16 July 2021

Published: 21 July 2021

Publisher's Note: MDPI stays neutra with regard to jurisdictional claims in published maps and institutional affiliations.

Copyright: (c) 2021 by the authors. Licensee MDPI, Basel, Switzerland. This article is an open access article distributed under the terms and conditions of the Creative Commons Attribution (CC BY) license (https:// creativecommons.org/licenses/by/ $4.0 /)$.

\begin{abstract}
Learning content in mathematics, such as vector geometry, is still predominantly taught in an abstract manner, as the visualization and interaction of three-dimensional problems are limited with classical forms of teaching such as blackboard lessons or exercise sheets. This research article proposes the use of augmented reality (AR) in mathematics education. The proposed approach aims at easing the learning process related to vector geometry currently taught in senior mathematics classes by using intuitive visualization. The article introduces the concept of AR and presents the didactic foundations and the influence on the learning process based on an extensive literature review. Although studies see great potential in the use of AR for teaching mathematics, the method has so far hardly been used in schools. This can be mainly explained by the technological entry barrier of AR and the lack of simple, robust AR applications, in particular for vector geometry. To fill this gap, the authors developed "cleARmaths", a developed android application for augmented reality-based teaching in vector geometry that allows widespread use. As a didactical concept, some example exercises sessions with the app are proposed, demonstrating how the app could be used in a mathematics classroom. Finally, the app was evaluated in a mathematics class and the results analyzed in a detailed study. It was found by the teacher and students to be beneficial and amusing, demonstrating the potential for AR in mathematics classes.
\end{abstract}

Keywords: augmented reality; mathematics education; vector geometry

\section{Introduction}

Understanding mathematical concepts and principles is essential for many fields of technology and science. Despite its great relevancy, mathematics does not enjoy a great popularity as a teaching subject in general. Studies estimate $17 \%$ of the population to be high in mathematical anxiety [1] (p. 197). As some math-anxious people do not perform poorly in mathematics, it is not conclusively answered if anxiety inevitably leads to poorer performance or vice versa [2,3]. Regardless of the causality, poor performance in mathematics in general, and for women in particular unfortunately, often leads to leaving the STEM (science, technology, engineering and mathematics) career path [4]. One reason for the partial unpopularity of the mathematics lessons and the teaching content lies in the abstract and theoretical way of teaching, which demands students to memorize but not necessarily to understand the subject $[2,4,5]$. The complex contents in mathematics education can often only be conveyed in a very abstract way due to the limited visualization possibilities of classical teaching methods like blackboard lessons or remote classes due to the COVID-19 pandemic. An important example is teaching in the subject of vector 
geometry, which will be tackled in this article. For all these reasons, it is important to deliver efficient educational activities and tools for mathematics that help the students overcome these challenges. These should aim to improve and simulate their interest and understanding of this discipline.

New technologies can make an important contribution to help solving this issue in the future. According to [6] (p. 189) "disruptive technological innovation is pervasive in all aspects of society" and today's students can be considered digital natives [7]. On the one hand, digitalization offers many opportunities to vary methods and to individualize the learning process in schools. On the other hand, the presence of digital devices is omnipresent and thus available for teaching purposes. In Germany, 95\% of the twelve- to nineteen-year-olds own a smartphone [8]. This promises increased acceptance of the use of new technologies in mathematics teaching in the years to come.

Augmented reality (AR) and virtual reality (VR) are fairly recent technologies that have a rising popularity. These are used in software for gaming, but also in a number of other domains (i.e., advertisement, education, etc.). AR and VR are increasingly used in educational apps, either for adults (to teach a physical manipulation for a job task for example) or for children. Indeed, AR and VR bring a number of advantages for the teaching process. Firstly, as it is not a traditional teaching method, it often arouses an initial interest and curiosity from participants, who mostly have rarely used it. Moreover, it allows interaction and visualization in $3 \mathrm{D}$ for some things that could never exist as 3D objects in reality, or that are not accessible physically for the students, and therefore give a better understanding of it; for example, visualizing the simulated airflow around a car. Interaction with the virtual content is materialized through a touch screen, a computer, hand gestures, voice or even with haptic gloves. Some of these interaction means can give a very intuitive feeling for the user.

The article will focus mainly on AR applications as they are often more accessible in terms of hardware availability and development software. This means is it more easily implementable in a school, and more potential researchers/developers can use this technology and develop apps.

\subsection{Aims and Structure of the Research}

There are only few studies on the benefits of AR for teaching mathematics, and therefore a lack of technical solutions that are suitable for use in teaching, and more particularly for vector geometry. As a result, AR is rarely used in mathematic classes. It is not included in any official mathematics program in Germany.

Therefore, this article aims to fill these gaps and addresses the use of AR in the school subject of mathematics and more particularly for vector geometry to improve on the current abstract teaching and learning process of mathematics. It aims to reveal the potential of AR in this context, and to provide a concrete teaching tool: a simple and robust AR app for vector geometry learning.

First, an overview of the concept of AR is presented. Afterwards, the didactical benefits from AR are derived, with a discussion on the effects on the learning process and its potential for teaching mathematics based on an extensive literature review. Following is a review of selected AR software projects for mathematics. Existing applications that deal with vector geometry are also presented, with their limitations. Furthermore, a technical implementation considering the literature review, the android application "cleARmaths", is described. Finally, the application is evaluated in a German 12th grade mathematics class, to assess more concretely the benefits of using AR to teach vector geometry.

\subsection{Concept of Augmented Reality}

According to [9] (p. 355), augmented reality is a technology used to overlay reality with virtual objects in real time and with the possibility of interaction (see Figure 1). Immersion, interactivity and real-time capability are three of the main requirements when it comes to AR [10]. Immersion is based on the idea that for a fully convincing AR, all 
senses must be addressed. The term immersion is also mentally or psychologically meant to describe the quality of the experience. Following this argumentation, the degree of immersion of an AR system depends on the strength of the feeling one experiences diving into the augmented world [10].

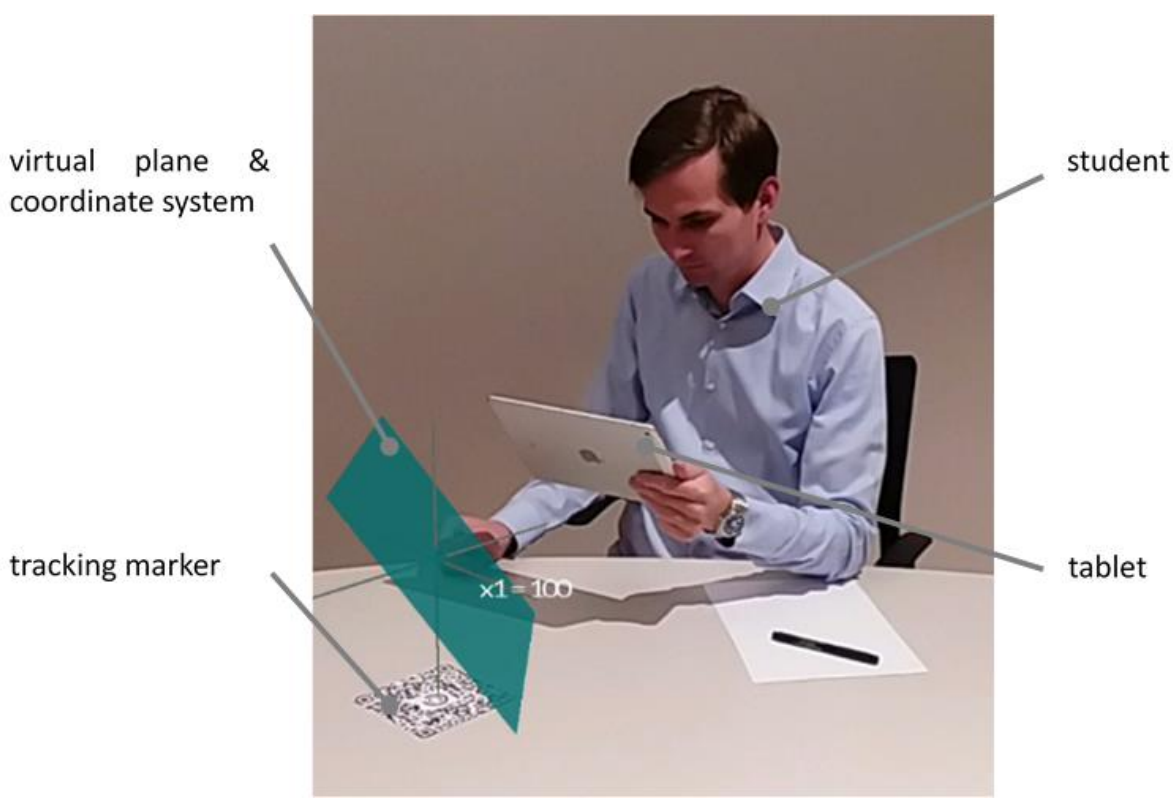

Figure 1. Video-see-through of cleARmaths: augmented reality visualization for vector geometry.

Interactivity between the user and AR means the controllability of 3D objects by the user [10], and real-time capability describes whether the system can respond to the user input in a time that is intuitive for human perception. High interactivity and realistic real-time representation both have a positive influence on immersion.

With the increasing computing power of mobile devices in recent years, augmented reality can be realized with smartphones or tablets [11]. For this purpose, the video-seethrough concept is used. Figure 1 shows the overlaying of the real environment with a virtual plane on a handheld tablet device, for a better understanding of the mathematical dependencies and parameters. First, a video stream on the device is recorded with the help of a calibrated camera. In the second step, tracking starts. According to [12] (p. 243), tracking means the continuous persecution of the "viewpoint[s] of the observer". In most cases, this is solved by determining the position of the camera in relation to the real world. It is then possible to register and anchor virtual objects in the real environment by an AR-marker, here in the form of a 2D image on paper. The visualization finally shows on the device's screen the superimposition of the virtual content and the real environment. These types of markers can be recognized in the video stream by image processing methods. The markers are inexpensive and lead to an acceptable computational complexity on modern mobile devices.

There are other tracking methods, such as markerless methods, which, e.g., detect corners or edges in the video stream, which are recognizable features of the visual environment. The obvious advantage is that no additional material is required apart from the device. However, these methods have a higher computational complexity. The used tracking method is not relevant for the presented research and may be subject to further investigations.

\section{The Potential of AR for Teaching Mathematics}

\subsection{Didactical Fundamentals of Augmented Reality}

"AR will steadily evolve during next ten years, becoming a popular everyday technology among the population, including educational environments" [13] (p. 482). There are already examples of popular non-educational applications used by a large number of 
people. For example, Pokémon GO started a trend for both adults and children in summer 2016 and thereby showed what potential AR has to offer. The question is, how can AR help to improve the learning process beside gaming aspects? Due to the high requirements, there are only few usable applications aimed at teaching so far. First, a didactical concept must form the basis, and this has to fit into the existing everyday life in schools. Second, the technical implementation must be comprehensible and useable even for non-tech-savvy students. In addition, the student has to be able to interact with the medium instead of just looking at it in a passive manner. As [14] stated, media do not fulfil an end in themselves. Therefore, a successful methodological realization in everyday teaching is essential. Media that meets these requirements are then tools that upgrade and above all enrich the learning process.

\subsubsection{Influence of Augmented Reality on the Learning Process}

A meta-review about AR in the education sector was published in 2014 [15]. The study discusses positive aspects (e.g., increased content understanding, long-term memory retention, improved physical task performance) and negative aspects (e.g., usability difficulties, ineffective classroom integration) that influence the learning process.

In studies such as [16], participants felt that they had to pay more attention while using AR systems. It has to be considered that most people were not familiar with these kinds of systems. How this novelty effect influenced the results remained open.

Regardless of this, it was found that physical tasks were easier to learn with AR support. In addition, a strengthening influence on long-term memory was observed. Furthermore, the motivation and the amusement of the students increased in the studies. That was also one of the results a study achieved by [17]. Besides that, the students found the use of an AR application much more pleasant than the alternative desktop software, although the usability of it was lower.

Another advantage is that the students' ability to work together is encouraged. AR technologies promote and support social skills. An example is the study by [18], in which second graders worked in groups on a shared display. The success of the method is not directly attributed to AR technology, but indicates that AR fosters such methods. The children dealt thematically with animal and vehicle names. They learned in a game-like environment with 3D models.

It turned out that particularly underperforming students benefited. High-performing children could gain comparatively little from it. As possible reasons, the authors stated that the potential for improvement is lower with already good performances and that underperforming children are often more perceptive to physical activities. It remains to be seen whether this physical confrontation will pay off in any other way for the highperforming children.

AR changes in any case the way of understanding by combining visual and sensory information. From this, [18] concluded that students more easily learn languages based on symbols when using AR applications. Further studies showed that this result applies to other aspects of learning as well. Subject matters in which the spatial imagination is addressed are explicitly mentioned. Another study [19] showed that learners understand chemical structures better when they learn with AR applications instead of using books. Spatial topics occur at school in chemistry, biology and especially in mathematics.

Interactivity, self-determination of learners, networking and collaboration, communication between learners and teachers are criteria for added value for the teaching and learning process state the authors [20]. Additionally, whether the enjoyment of the students is greater is considered. Above all, the use of new media is said to have a great chance of putting these criteria into practice.

However, the authors relativize this aspect. Media must first be usefully placed in a learning situation in order to be able to increase the quality of learning. The teaching and learning process is a construct, "which results from the interaction of many factors" [20]. However, these cannot be defined exactly. Thus, there is no "comprehensive understanding 
of quality" [20], just as there are no individual definable parameters from which conclusions could be drawn for the evaluation of didactic benefit [20]. To maximize learning outcomes the pedagogical needs of the learner have to be considered carefully states [21] as "the prerequisite for an effective learning environment is its pedagogical approach" state [22] (p. 774).

Nevertheless, the authors found only a few studies explicitly having a theoretical underlying concept [22]. This is linked to the question of whether the use of AR technologies improves the teaching and learning process. Firstly, the positive effects on the learning process represent a very important part and also connect to the criteria by [20]. However, everyday teaching practice is not yet considered. The theoretical foundation is necessary, but not fully sufficient. Ref. [22] (p. 3) "demand the development of a specially created didactic design and its realization in a (complex) teaching situation" in order to create benefit by the use of media. The underlying concept is one of the decisive characteristics of an AR application, fulfilling the pedagogical needs and creating a beneficial learning environment.

\subsubsection{Importance of Spatial Imagination}

Augmented reality works with 3D visualizations in real space. Thus, the technology is directly connected to the learning content when used in subject matters with requirements for spatial imagination. At school, this is particularly found in the geometry classes in mathematics. When crossing a road, it is necessary to estimate the distance to a car, how fast it gets closer and how long it takes to cross the road. Assembling a piece of furniture requires an understanding of how to identify and position the parts and their positions according to the plan. In ball sports, it is important for players to observe the positions of their teammates and opponents and how it will change over the next few seconds. There are many situations that can be solved by spatial imagination. It plays an important role in numerous professions [23]. Therefore, it is not surprising that it is frequently checked in recruitment tests. This is supported by a model of [24]. The author takes the view that the spatial imagination is one of seven primary intellectual abilities.

Beyond that and according to [25], there is a positive correlation between visualspatial imagination and mathematical achievement. However, there is no proof of causality. Ref. [26] assumes that visual perception precedes spatial imagination and describes the collection of memories of seen objects as a basis. Only afterwards is it possible to imagine objects only in thought or to modify them mentally.

In school, the spatial imagination is trained primarily in geometry lessons. This is usually done with printed media, desktop software or with tools such as real models, 2D drawings and 2D sketches. Solving geometric problems in the mind is another subcategory according to [26]. However, in a comparison of potential teaching methods, AR technologies would be more beneficial for training spatial imagination [15].

\subsection{An Overview of Augmented Reality Applications in Teaching Mathematics}

Starting at grade nine in Germany, geometry classes deal with analytical geometry, which is used to describe the space we live in with algebraic methods [27]. The use of AR in the development of an application for analytical geometry in mathematics classes is therefore appropriate. There have been publications about this topic since about 2000 [28].

It was demonstrated in a study that the use of augmented reality and virtual reality improves the training of spatial imagination [29]. The participants worked with 2D plans, desktop software or a VR system on a 3D design. The goal was to name the most effective working environment for the design process of architects and according to [29], this property is directly associated with spatial imagination.

Nevertheless, AR has not yet arrived in the mathematical everyday life of schools. $\mathrm{AR}$ representations of $3 \mathrm{D}$ objects are actually available in three dimensions in contrast to desktop representations. Additionally, the visual perception creates memories that are used to improve spatial imagination further [26]. The user himself creates, edits, 
combines, changes and deletes geometric objects, in contrast to many common media. The importance of this can be seen in the work by [30]. Especially through interaction with the objects, the improvement of the understanding takes place. The actual benefit for the learning process depends directly on the potential of the used AR for the specific situation [30]. Thus, the underlying methodological and didactical concept are important. Furthermore, [31] connected movement with spatial imagination and stated: participants who moved themselves around the 3D model benefited significantly more than participants who only moved the model. This is possible by registration of virtual content in the real world, but not with traditional media.

Extensive scientific work exists regarding the usability of AR in mathematical education. However, most of the applications discussed do not deal with vector geometry, but with other various mathematical topics. Six of such articles/applications were examined [32-37], and their main characteristics and findings regrouped in Table 1. All are fairly recent and were done in different countries, which shows the rising popularity of this topic worldwide.

Table 1. Overview of different AR applications for mathematics teaching.

\begin{tabular}{|c|c|c|c|c|c|c|}
\hline & [32] & [33] & [34] & [35] & [36] & [37] \\
\hline Year & $\mathrm{X}^{1}$ & 2019 & 2021 & 2016 & 2019 & 2019 \\
\hline Country & Singapore & India & Spain/Italy & USA & Indonesia & China \\
\hline Cost & $20 \$ / 6$ months & Free & $x$ & $\mathrm{X}$ & $x$ & $x$ \\
\hline Availability & Apple store & Website (apk) & Not public & Not public & Not public & Not public \\
\hline Platform & iOS & Android & Android & $x$ & $X$ & $x$ \\
\hline Subject & $\begin{array}{c}\text { 3D solids, } \\
\text { graphs, } \\
\text { trigonometry }\end{array}$ & $\begin{array}{l}\text { 3D geometric } \\
\text { objects }\end{array}$ & $\begin{array}{l}\text { Multiplication } \\
\text { tables }\end{array}$ & $\begin{array}{l}\text { Operations, } \\
\text { numbers, } \\
\text { measures }\end{array}$ & 3D geometric objects & $\begin{array}{l}\text { Statistics \& } \\
\text { probability }\end{array}$ \\
\hline Age group & $x$ & 14 years old & $8-9$ years old & $6-7$ years old & $14-15$ years old & 13-15 years old \\
\hline $\begin{array}{c}\text { Type of AR } \\
\text { marker }\end{array}$ & 2D image & $\begin{array}{l}\text { 2D image/ } \\
\text { textbook page }\end{array}$ & Ground plane & 2D image & 2D image & 2D image \\
\hline $\begin{array}{l}\text { Development } \\
\text { soft-ware }\end{array}$ & Unity/ARKit & Unity/Vuforia & Unity/Vuforia & $x$ & Augment & $x$ \\
\hline $\begin{array}{l}\text { Interaction } \\
\text { level }\end{array}$ & $\begin{array}{c}\text { Limited } \\
\text { (view only) }\end{array}$ & Good (exercises) & $\begin{array}{c}\text { Good } \\
\text { (mini-games) }\end{array}$ & Good (exercises) & Moderate & Good \\
\hline $\begin{array}{l}\text { Feedback from } \\
\text { study }\end{array}$ & $x$ & $x$ & $\begin{array}{l}\text { Good enjoy- } \\
\text { ment/easy to } \\
\text { use/no stress }\end{array}$ & $\begin{array}{c}\text { Teachers were } \\
\text { enthusias- } \\
\text { tic/reveals } \\
\text { potential and } \\
\text { need for AR for } \\
\text { math classes }\end{array}$ & $\begin{array}{c}\text { Easy to under- } \\
\text { stand/fun/interactive }\end{array}$ & $\begin{array}{l}\text { Results dependent } \\
\text { on student } \\
\text { self-efficacy. Overall } \\
\text { good results }\end{array}$ \\
\hline
\end{tabular}

${ }^{1}$ : No information found.

All of them are developed for handheld devices, as these are widely available and the development process of such apps is easier than for HMDs. Indeed, the majority of them are developed on the game engine Unity, with the Vuforia plugin for AR, built for Android. The augmented content is for most applications augmented on a 2D paper with an image, except [34], which uses ground plane (for which any plane surface in the real world can be used).

The topics implemented in these apps are diverse: they deal with mathematical operations, geometric objects or trigonometry. They can in principle all be used by the students alone, without needing special material from the classroom. However, most of the apps were used under the supervision of teachers or researchers.

Most applications include a high degree of interaction with the possibility to do exercises in-app.

All applications tested with teachers or students report good feedback: ease of understanding, fun, interaction and reduced stress. Overall, teachers see a great potential for AR in mathematics to teach some particular topics like geometry or measurement [35]. 
It is important to notice that most of these apps are not available and were used only during the time of the study, and therefore are not accessible at the moment for any teacher or student.

As seen in the previous overview, many of these applications deal with geometry, but none use vector geometry with parametric equations. To the authors' knowledge, only two AR applications exist on this topic: Construct3D and GeoGebra AR.

Released in 2000, the 3D mathematics software Construct3D [28] is aimed at teaching geometry. It is published and is explicitly developed for the education sector of schools and universities. The application allows the user to visualize elementary geometric objects as AR by using Head-Mounted Displays (HMDs). The input is done by a freely movable pen in connection with a Tablet-PC and up to two persons can work on one model. However, HMDs are still expensive compared to standard devices like smartphones and limit the number of same-time users. This software was ground-breaking at the time but is now obsolete in regard to today's available technology.

In 2017, the application GeoGebra augmented reality [38] was released. It was published by the non-profit organization International GeoGebra Institute. Function equations can be displayed and modified in this augmented reality application. In addition, there are other geometrical objects such as the Penrose triangle. GeoGebra augmented reality deals with the current topics of analytical geometry in senior classes [32]. It is easily accessible via mobile devices, but the design and functionality are rather designed for technically affine learners. The GeoGebra website offers some exercises that make good use of AR, such as overlapping certain geometric objects defined with parametric equations, on real corresponding objects. For example, an asymmetric oval can be overlapped over an egg. Overall, the application is well realized with various resources to use with it. However, as it was designed to be very complete, the first use can be complicated for students (inputting equations, for example). It seems, therefore, aimed at older or more advanced students. Using such an application could benefit children that are already comfortable in mathematics to further their knowledge. However, due to its complexity, it could potentially confuse and stress less advanced students.

In summary, a number of AR applications to teach mathematics already exist and shows it is a promising domain. However, most of them are part of studies and not freely available. Only two deal with vector geometry, with GeoGebra AR being the most actual and complete. However, the target audience for it is technically affine. For a broad application in mathematics teaching, it is necessary that access to the teaching content is as simple and interactive as possible. It is to answer this need that cleARmaths was developed.

\section{CleARmaths: A Simple and Robust AR Application for Teaching Vector Geometry}

\subsection{Concept and Functions of the Application}

Based on the described constraints, a stand-alone augmented reality was developed as part of this research work, which was designed for use in teaching. The application was developed with the goal of enabling students to visualize and study geometric objects like planes, lines, and points in a 3D coordinate system in augmented reality, while only using a smartphone or a tablet. Special attention was paid to the simple interactivity of the application. Figure 2 shows the relationship between the input of the student and the visualization in the developed augmented reality application named "cleARmaths". 


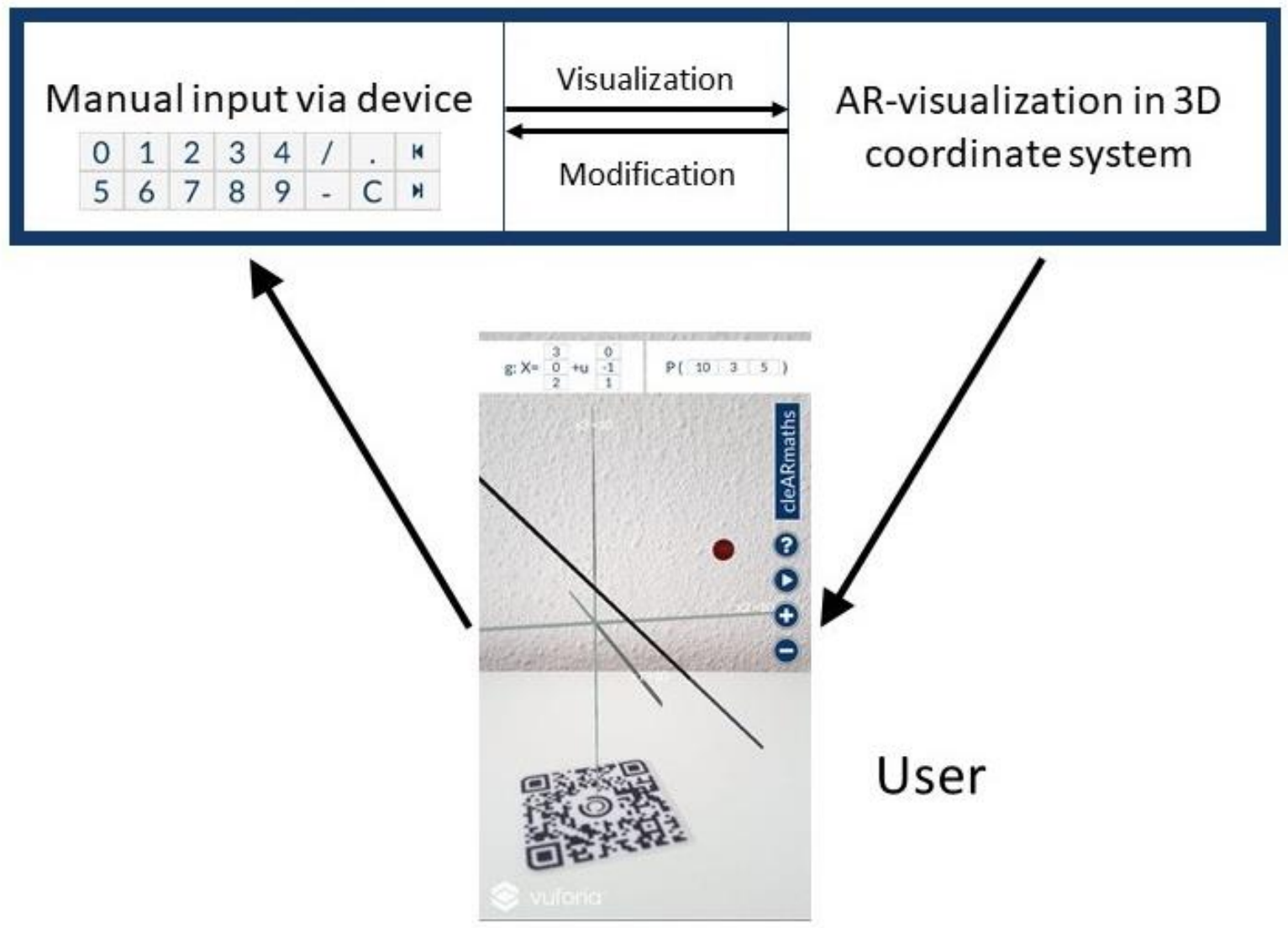

Figure 2. Basic concept of the developed AR application for teaching vector geometry (version $0.1 \mathrm{r} 0$ ).

Students can enter the parameters of the equations and see the visual impact of their changes. Indeed, the figures are displayed according to their coordinates, anchored with a marker in the world. This way, students get a sense of the 3D component by moving around the figures with the handheld device.

In the background, the application performs calculations to provide the students with further information. For example, intersections are automatically calculated and displayed in the visualization. Students can use this information to check their own calculations and to create new calculation tasks.

Figure 3 shows the user interface of the developed application in more detail. The design is plain and the number of operating options is as low as possible without restricting functionality. Furthermore, the user is mainly guided by symbols and not by text to keep it as intuitive as possible. Interaction takes place directly through the selection and editing of geometric objects.

The user interface can be divided into five areas:

1. Fields for displaying the object equations.

2. The keyboard opens when 1 is pressed. The buttons with arrow symbols allow to activate and edit the input fields one after the other. Touching individual input fields has the same effect. An active field is highlighted in light blue.

3. Selection between the object equations of plane, line and point.

4. Buttons for canceling input and closing the keyboard.

5. Buttons (from top to bottom) for general information, a short user manual, scaling and pausing the visualization and displaying/ hiding the intersection 

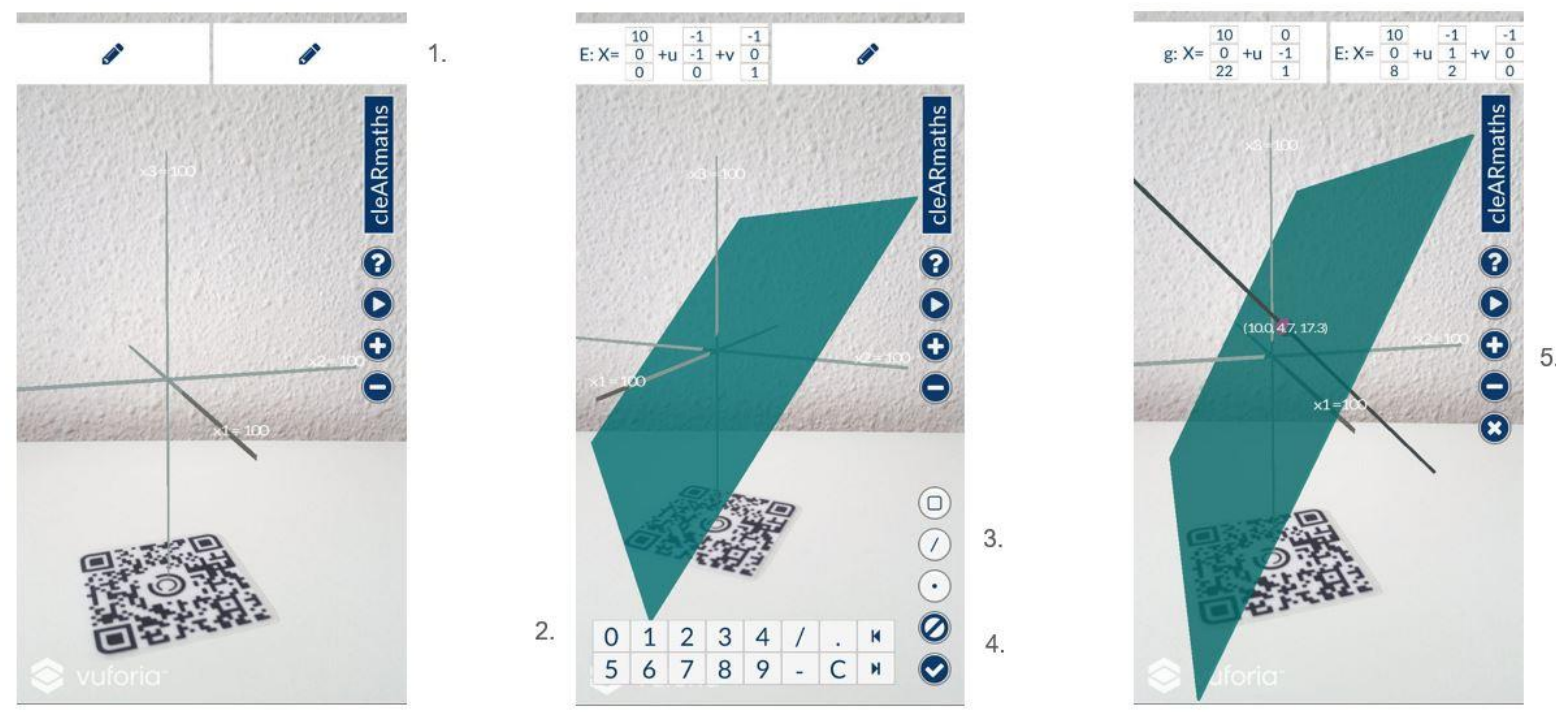

Figure 3. User interface of the developed application cleARmaths (0.1r0).

A recent update to the app (0.2r0) allows, on top of the previous functionalities, the user to scan a new kind of marker in order to directly visualize the geometric figure(s) without having to input the coordinates manually (see Figure 4). This functionality is particularly relevant for sessions with exercise sheets where the students only comment on what they see and do not need to change the numerical values of parameters. A marker generator and sample exercise sheets are available on the cleARmaths website [39]. These can be used by teachers to create custom exercises. For further information about the creation of custom exercise sheets, please reference Appendix A.

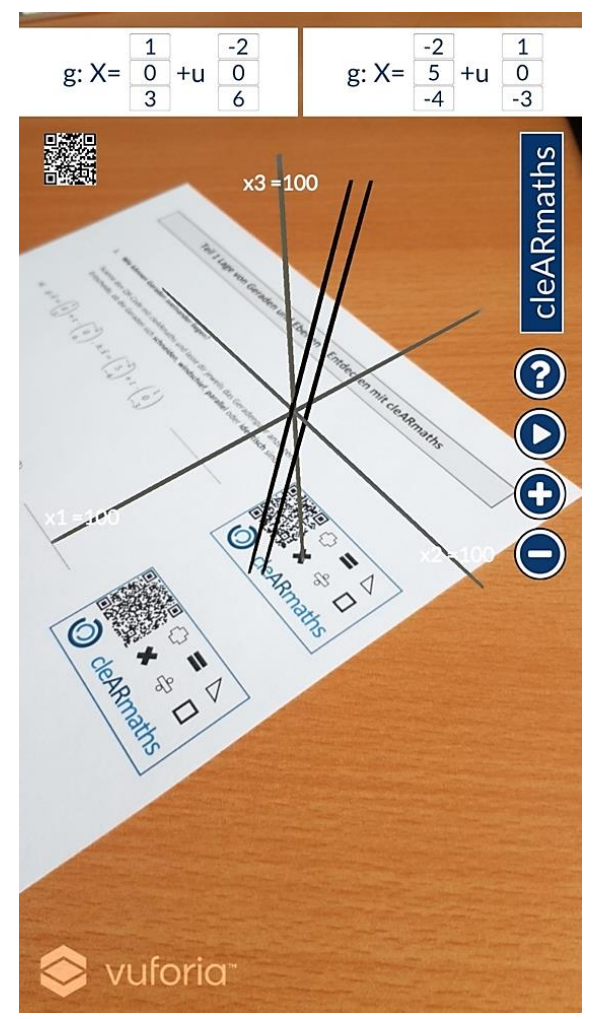

Figure 4. Augmented reality extension of an exercise sheet in a mathematics lesson on vector geometry (0.2r0). 
Additional hardware is not necessary and there is no need for the user to be technophile. In terms of using mobile devices the immersion is lower than in terms of using an HMD. The display of a smartphone is not 3D capable and therefore stereoscopic vision is not supported. As students are the target group, the advantages of using mobile devices outweighed. Nevertheless, video recording, tracking, registration and visualization are comparable to other AR systems for the requirements presented in this paper.

\subsection{Technical Realization}

The implementation is based on the cross-platform game engine Unity [34]. For the registration process of the virtual objects and the tracking of the marker, the AR software development kit Vuforia [35] was used. The application is implemented as a mobile application and is available to download for android devices (cleARmaths can be downloaded from the Google Play Store [36] or on the cleARmaths website [39]).

In Unity, the code is structured in scripts, which are also unique classes. Classes can inherit from the Unity base class "Monobehaviour". In this case, scripts generally represent components or properties of "GameObjects".

The structure of the cleARmaths program is described on Figure 5. On the picture, all classes marked with "**" inherit from the Monobehaviour base class. A shallow pointing arrow leads from a derived class to the base class. A pointing arrow represents an interaction between two classes. For example, cleAR_UI_Control accesses cleAR_UI_ScaleLabel.

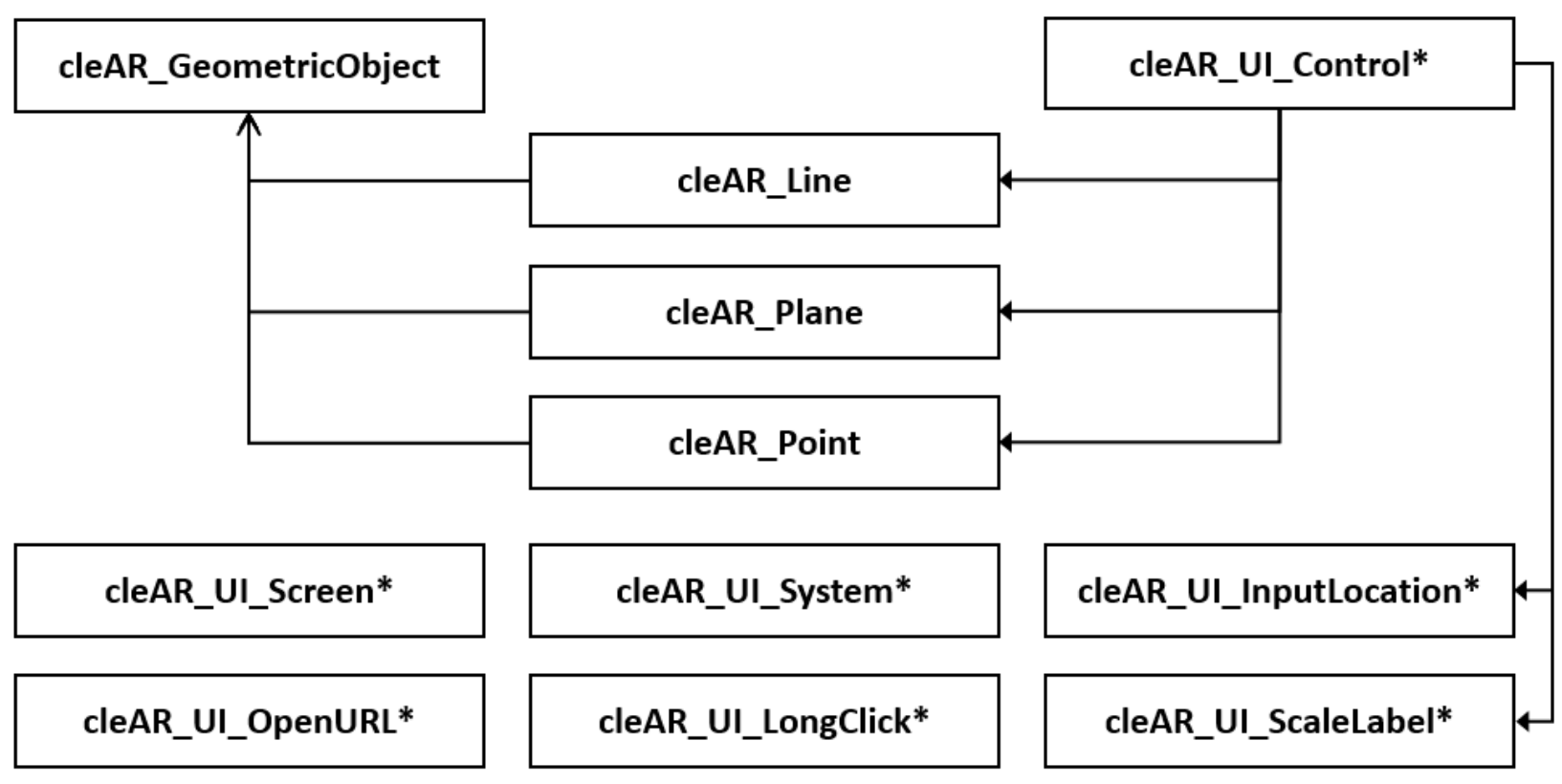

Figure 5. Simplified representation of the classes from the cleARmaths program in Unity.

The custom markers containing object definitions use QR codes to encode the object equations. These $Q R$ codes can be scanned using the smartphone's camera and are decoded by the cleARmaths app, using the Zxing module [40] ported to C\#. QR codes contain information as combinations of characters such as numbers or letters (called a "string"), they are for example commonly used for web URLs. They therefore allow for quick input of information by scanning, instead of a laborious manual input. In cleARmaths, the encoded string contains data on how many figures need to be displayed, what their types are (line, plane or point) and their coordinates.

The QR code generator webpage [39] is written in java script to allow for fast clientside execution and compatibility with all major browsers. Additionally, modern responsive web design is used to ensure a good user experience on different screen sizes and especially on mobile devices. The $\mathrm{QR}$ codes are generated from user input by the qrcodes.js 
framework [41]. After that, the QR code is integrated into the marker image using HTML $5^{\prime}$ s canvas feature. The finished marker can then be downloaded as a. png image file. This java script is integrated into the cleARmaths website's WordPress [42] content management system. This approach is preferred over a static webpage to ensure easy editing of the websites content and to achieve a consistent appearance theme across the whole website.

\subsection{Didactical Concept}

The app, by means of its simple concept, can be used independently by each student. Students can get to know the app by either reading the instructions on the website [39] or from minimal instructions by the teacher. Thanks to that, the students are able to freely explore the $3 \mathrm{D}$ space at their own pace. This could possibly mitigate the stress experienced by some students in traditional mathematics classes.

The authors have created dedicated exercises that aim to be used in mathematics classes or at home. With such tasks, the student is motivated to spend more time using the app, actively trying to solve the proposed problems.

Exercises can be designed without any manual input from the students, by using the QR code markers. An example exercise sheet can be found in Appendix A. In this case, the students are in an observative position. The students look at different configurations and have to comment on what they see, or answer related questions. As they do not need to input the coordinates themselves, it removes the interaction with the coordinate parameters. Possible advantages of this system are reduced stress in students with math anxiety and less time spent copying numbers. It is also easier for teachers to ensure that the whole class sees the same figures, since input mistakes are impossible with this system.

Another type of exercise uses the manual input of parameters, with examples provided in Appendix B. In this case, the student can observe the influence of changing each coordinate parameter on the displayed figures. This improves the students' understanding of the notion of the three dimensions of space, mathematically described as three parameters, $(x, y, z)$. In a more advanced teaching unit, intersection proven analytically by manual calculation, can be visually checked, giving a tangible aspect to these equations.

The relevant aspects of teaching mathematics are summarized in three categories [43]: movement, cognition and collaboration. In addition to the already mentioned aspects of spatial imagination, the authors also include intuitive interaction opportunities to the category movement. In this way, students can rely on their experiences from the real environment. The resulting reduction in the complexity of the representation is intended to focus the actual learning content. AR fosters collaboration because it is possible to use virtual learning content and still communicate and collaborate face to face. Each person or small group has its own access to the learning content and the possibility to interact individually. The presented software system additionally has potential usage beyond mathematics and the modular structure could allow further development for other areas such as biology or chemistry.

\section{Evaluation of the cleARmaths App in a Mathematics Class}

In order to investigate the app's potential for teaching vector geometry in a real schooling situation, it was introduced during a mathematics class to twelfth-graders at a German high school (16-17 years old) on 21 May 2021. The study has 15 participants in total, and the session was led under the supervision of the mathematics teacher.

Along with three exercises sheets, one page explaining succinctly how to use cleARmaths was given to the students. The teacher did not explain anything or help the students in any way during the session.

\subsection{Types of Exercises Proposed}

For this purpose, three exercises were created, which were to be answered by the students of the class. The exercises sheets consisted of a first set of questions to answer without the help of the cleARmaths app. For example, they had a photo of a screenshot of 
cleARmaths (see Figure 6), and had to answer the following question: "Could you say that in a 3D room, the following red lines have an intersection?". After answering on the paper, for each question, they then could scan a QR code to check their answer in 3D directly with the cleARmaths application. This allows us to have an idea about their perception of the $3 \mathrm{D}$ world, projected in 2D.

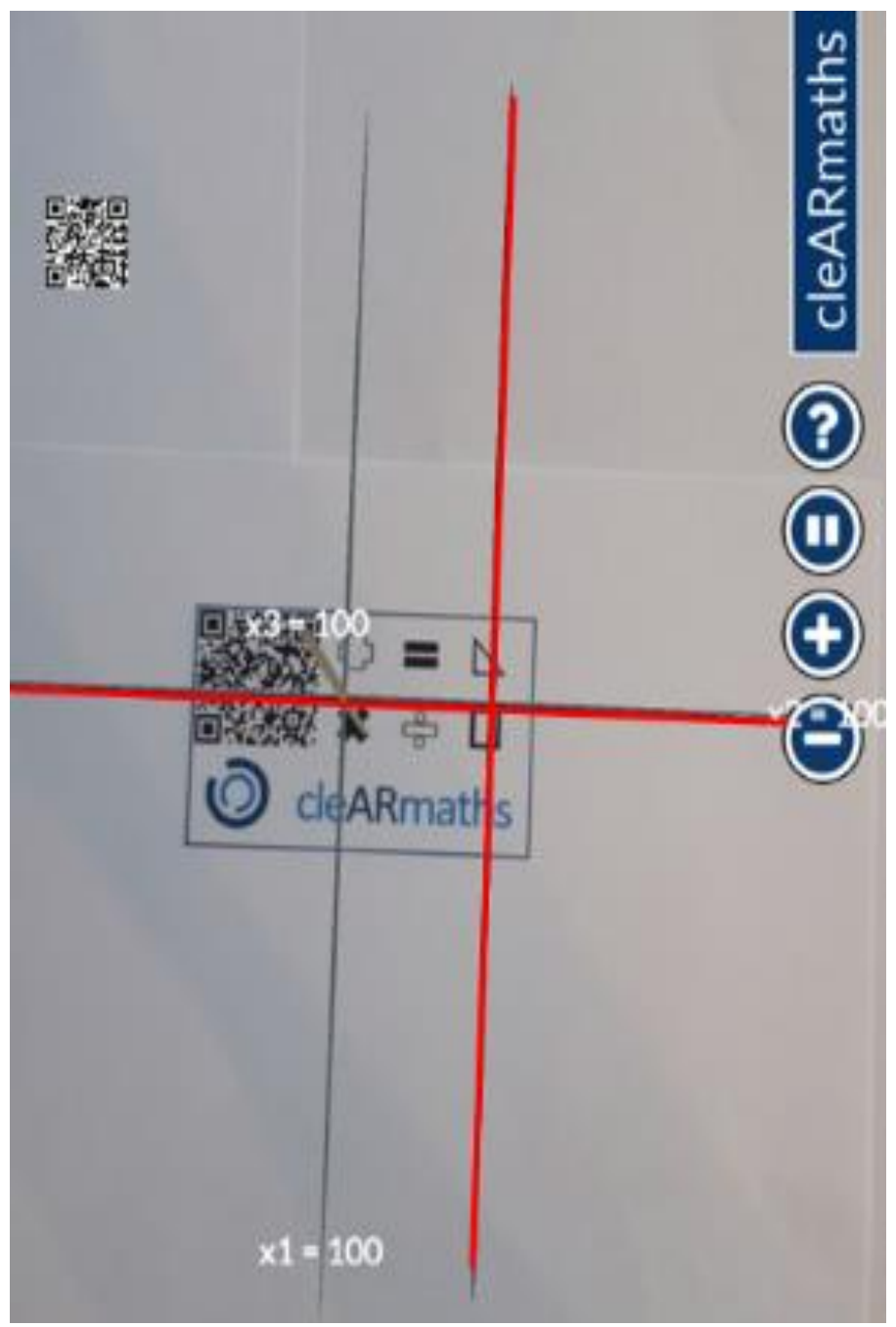

Figure 6. Image sample from one exercise sheet from the cleARmaths study.

\subsection{Feedback from the Students}

After the students completed the tasks, they were given statements from the following categories about the app, and had to give a rating on a scale from one to five, one being "I do not agree at all" and five being "I fully agree".

- Usefulness;

- $\quad$ Ease of use;

- Relevance of the tasks performed; and

- Need for optimization.

To check for consistency in the answers of the students relative to the marking scale, some statements were formulated in a positive manner, for example: "I would like to see the app integrated more into the mathematics lessons."; while other statements were constructed with a negative tone, i.e., "The app does not bring any relief". Overall, the answers were consistent. 
According to the students' assessments, the majority had no to few misconceptions of three-dimensional space before. Nevertheless, most of them believe that the app makes it easier to work on mathematical tasks and does not require too much effort. A larger proportion of the students assume that using the app has a positive effect on their ability to think in three-dimensional space.

The utilization of cleARmaths was not perceived as too complex and thus easy to use. Furthermore, the students find that the application options are well designed. Only a small group of students recognizes inconsistencies in the application. The amusement factor from working on tasks with the help of the app was average to high.

The exercises are only moderately suitable to show comprehension problems. However, the tasks were able to correct existing misconceptions, according to the students. The majority also found that the tasks to be performed were not boring. Furthermore, the students had never performed such types of exercises and were happy to discover something new and would like to see more of these types of tasks in mathematic classes.

They were also asked to answer open questions, in order to get feedback for improvement and more details about their opinions.

The first question asked was "what would make the app easier to use?".

Small bugs were found by the students, which have since then been easily corrected. Furthermore, the short instruction sheet of cleARmaths provided by the teacher should be equipped with more details about the functions. The cleARmaths website has more detailed instructions, and this shows these would be useful, the teacher would not have to write any additional material for explanations, and the students could manage by themselves. They also observed that the straight lines and axes could be made more distinguishable. The students also found the QR code fields on the markers were too large and they would like to see them minimized.

The second question asked was "how could the app be used meaningfully in the classroom?".

According to the students, cleARmaths could be used to correct homework and illustrate exercises. Already solved tasks could be checked with the app, and it could also help to simplify the introduction to new topics.

The third and last question was "what other functions should the app have?"

They would like to create their own straight lines and color them. This could be done with the QR code generator, and the color option could be implemented in a future version. This shows the interest of students for playful interaction and creation. A large part of the class would also like to see an iOS version of the app.

\subsection{Feedback from the Teacher and Conclusion of the Study}

After the class completed the tasks, an interview was conducted with the teacher. According to her, the third task could not be solved by the students, since the necessary prior knowledge was lacking. Indeed, the task was precisely about parametric parameters which are taught later. In this particular case, the QR code was really useful as students did not have to enter parametric equations themselves. She considered the other two tasks as very goal-oriented and she perceived the lesson to have a largely positive effect. The students worked mostly independently. Lastly, she mentioned that the students consider the idea of using AR in mathematics lessons as very positive.

This study showed that both teacher and students are motivated to use AR for mathematics on occasion. Further studies could elaborate and investigate on a complete plan for regular use of such applications, integrated with the official programs. Students were intrigued, but still at ease with the technology and the app in itself. They enjoyed themselves even if they are already in an advanced age group. The app seems therefore adapted and promising for this age group, this particular subject of vector geometry, to be used in a mathematics class. 


\section{Conclusions}

Abstract mathematics learning content like vector geometry is still a barrier for many students. This article proposes the use of augmented reality to overcome these challenges. For this purpose, the influence on the learning process and the didactic interactions were presented with an extensive literature review. Due to the lack of available intuitive software systems, the method has hardly been used so far in schools. The research work therefore presents a modular augmented reality application, which enables the visualization of geometric objects overlaid on the real environment.

The application, robust and with a simple design, aims to facilitate the understanding of vector geometry and parametric equations. It actively involves the student, who can themself interactively change the type of figures and their parameters, testing at its own pace. The augmented reality helps with spatial imagination, which can be hard to realize with more traditional 2D material. The app can be used in schools with corresponding exercise materials, with some examples given in this article. Moreover, it could be an amusing and original assignment for home-schooling, needing only a smartphone or a tablet (from the parents for example) during these times of pandemic.

The conducted study showed promising results, helping the students further their understanding of 3D space, in a playful and didactical manner. No particular stress was reported by the students. The teacher also found the app adapted to deal with vector geometry. The ease of use of the app with the QR codes was a major feature.

Furthermore, new additional functionality possibilities are numerous: such as adding other 3D geometric figures or allowing the user to see the 2D shape created by the intersect of a plane and a sphere. In-app exercises could also be implemented, while keeping in mind how to have an easy interface and functions to avoid overwhelming the students.

Author Contributions: Conceptualization, S.S., M.S., S.R. and M.J.K.; methodology, S.S., M.W. and M.J.K.; software, S.S., M.S., M.W., T.P., J.S. and M.J.K.; formal analysis, S.S.; investigation, S.S.; writing-original draft, S.S. and M.S.; data curation, M.S. and M.W.; visualization, S.S. and M.S.; writing-review and editing, M.S., M.W., T.P., D.T., M.R., N.H.-M., S.R. and M.J.K.; validation, T.P. and M.J.K.; evaluation, P.B.; funding acquisition S.R. and M.J.K.; resources S.R. and M.J.K.; project administration, M.J.K. All authors have read and agreed to the published version of the manuscript.

Funding: This research received no external funding.

Institutional Review Board Statement: Ethical review and approval was waived for this study, as it is a learning-based app that only trains mathematical understanding.

Informed Consent Statement: Informed consent was obtained from all subjects involved in the study.

Conflicts of Interest: The authors declare no conflict of interest.

\section{Appendix A Designing a Teaching Unit Using QR Codes}

The aim of this section is to serve as guidance and inspiration for teachers looking to create their own custom exercise sheets.

Custom exercise sheets are easily created using the cleARmaths generator on the cleARmaths website [39] (see Figure A1). New geometric objects (up to a maximum of 2) can be selected from the dropdown menu and added using the add button. Individual objects can be deleted with the minus to the left of the heading of each object. After inputting all values for the object equations, the marker can be generated by clicking the "generate QR code" button. The finished marker can then be directly tested and downloaded as a .png image file. This image can then be used in any word processing application to create a custom worksheet. 


\section{CleARmaths generator}

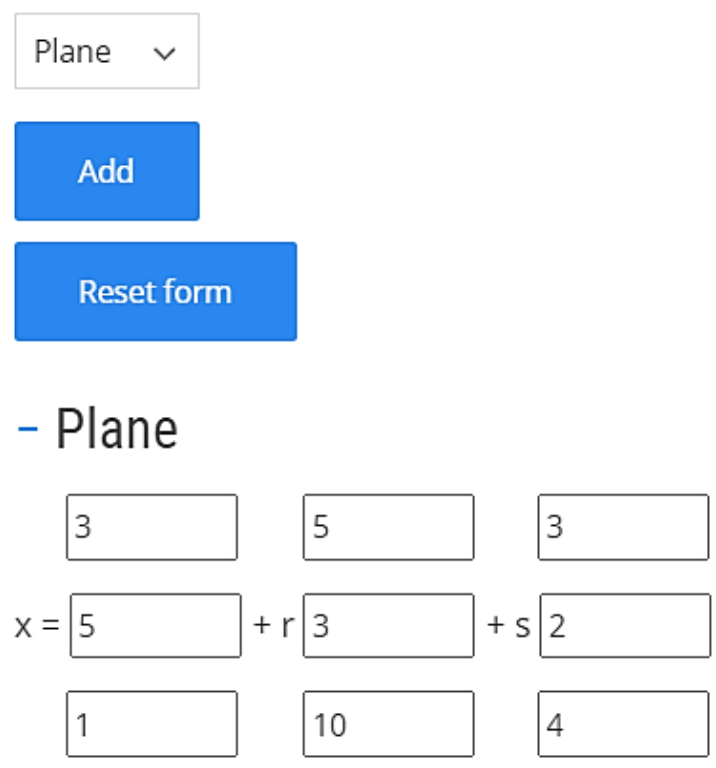

Generate QR code

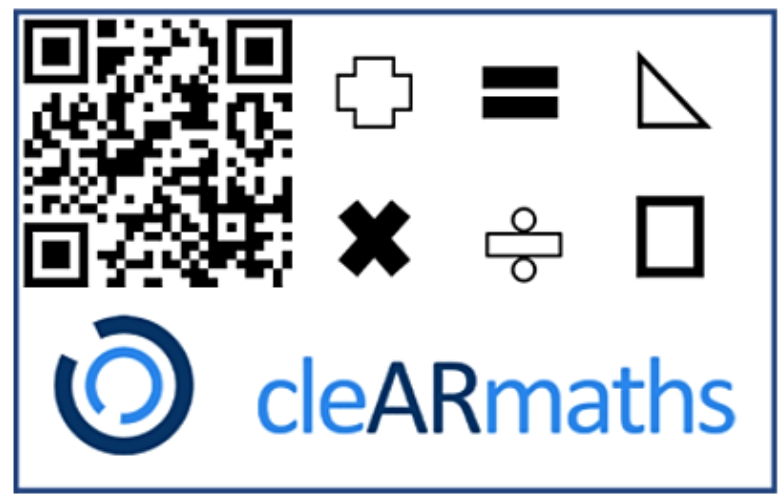

Figure A1. CleARmaths generator: this webpage can be used to create custom markers that contain equations for geometric objects.

The finished QR code can be scanned by pressing the QR code button in the top left corner of the cleAR maths app. Figure A2 contains an example exercise sheet. This can be used as a starting point and offers inspiration for a didactical application of cleARmaths in a mathematics class. 
Part 1 spatial relation of planes and lines - exploring with cleARmaths

1. Spatial relation of lines

Scan the cleARmaths qr-code on the right of the page and decide whether the lines intersect, are skew lines, parallel lines or identical lines.

a) $g: \vec{x}=\left(\begin{array}{l}1 \\ 0 \\ 3\end{array}\right)+t \cdot\left(\begin{array}{c}-2 \\ 0 \\ 6\end{array}\right), h: \vec{x}=\left(\begin{array}{c}-2 \\ 5 \\ -4\end{array}\right)+t \cdot\left(\begin{array}{c}1 \\ 0 \\ -3\end{array}\right)$ parallel

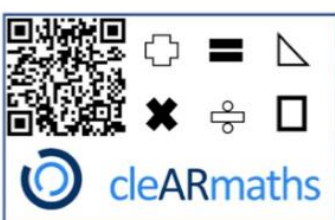

b) $g: \vec{x}=\left(\begin{array}{c}-1 \\ 1 \\ 2\end{array}\right)+t \cdot\left(\begin{array}{l}2 \\ 3 \\ 2\end{array}\right), h: \vec{x}=\left(\begin{array}{c}-1 \\ 0 \\ -2\end{array}\right)+t \cdot\left(\begin{array}{c}-2 \\ 3 \\ -2\end{array}\right)$

skew

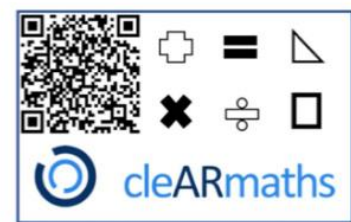

2. Spatial relation of planes

Scan the cleARmaths qr-code on the right of the page and decide whether the planes intersect, are parallel or identical planes.

a) $E_{1}: \vec{x}=\left(\begin{array}{l}1 \\ 0 \\ 2\end{array}\right)+t \cdot\left(\begin{array}{c}-3 \\ 2 \\ -2\end{array}\right)+s \cdot\left(\begin{array}{c}-1 \\ 1 \\ 3\end{array}\right), E_{2}: \vec{x}=\left(\begin{array}{c}3 \\ 3 \\ -1\end{array}\right)+t \cdot\left(\begin{array}{c}1 \\ 1 \\ -3\end{array}\right)+s \cdot\left(\begin{array}{l}0 \\ 0 \\ 6\end{array}\right)$ intersect

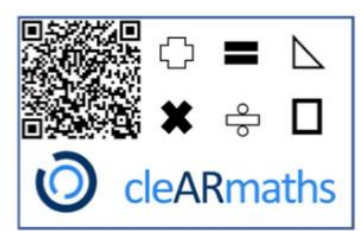

b) $E_{1}: \vec{x}=\left(\begin{array}{c}-2 \\ 0 \\ -1\end{array}\right)+t \cdot\left(\begin{array}{c}1 \\ 4 \\ -2\end{array}\right)+s \cdot\left(\begin{array}{c}3 \\ -6 \\ 9\end{array}\right), E_{2}: \vec{x}=\left(\begin{array}{c}7 \\ -6 \\ 8\end{array}\right)+t \cdot\left(\begin{array}{c}-4 \\ 2 \\ -7\end{array}\right)+s \cdot\left(\begin{array}{c}-1 \\ -10 \\ 7\end{array}\right)$

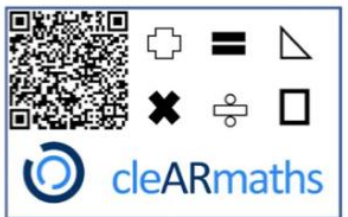
parallel

\section{(3) cleARmaths}

Figure A2. Example worksheet with solution.

\section{Appendix B Exemplary Design of a Teaching Unit with Manual Input}

This section presents a draft for dealing with vector geometry in a mathematics class, including the use of the presented concept and developed application. The proposed teaching unit describes an introduction to the topic of the relation of two vectors. In order to discuss these tasks in class, the students must be familiar with the vector concept, calculating with vectors (addition, subtraction, scalar product), spatial vectors, linear 
equation system, linear (in)dependence and with the graphical visualization of points and vectors in 3D coordinate systems. The proposed realization is divided into three parts:

Phase 1: The students get together in groups of two and are given the following task:

Which relative positions are possible between two lines? Remember the 2D case, what are the possibilities here? Enter two lines in cleARmaths and look at them from all sides.

Each group needs a mobile device with the augmented reality application installed. Then, they work on the task by trying different line equations. This phase is intentionally open and challenging. The step to Phase 2 is therefore particularly important. If learners do not succeed, they get access to Phase 2 as a kind of help. If they discover all four cases themselves, Phase 2 is only the verification and continuation.

Phase 2: The students are given the following line equations. The task is: Match values to the variables $\mathrm{a}$ and $\mathrm{b}$ so that the two lines $\mathrm{g}$ and $\mathrm{h}$ have an intersection, are identical, parallel or skew:

$$
g: \vec{x}=\left(\begin{array}{c}
-2 \\
4 \\
a
\end{array}\right)+t\left(\begin{array}{c}
6 \\
-8 \\
-12
\end{array}\right), t \in \mathbb{R} \text { and } h: \vec{x}=\left(\begin{array}{l}
1 \\
0 \\
0
\end{array}\right)+s\left(\begin{array}{c}
-3 \\
b \\
6
\end{array}\right), s \in \mathbb{R}
$$

The benefit of using augmented reality is particularly noticeable in the case where the lines are skew. A 2D visualization always gives the impression that the lines intersect. In augmented reality, this problem can be better illustrated. At the end of Phase 2, two groups get together and exchange their ideas. Afterwards the students work in Phase 3 in new groups of two.

Phase 3: At this point, it is possible to provide a practical reference in a motivating way. An imaginable theme is tunnel construction. A small historical embedding takes place: the class is a group of gold diggers and needs two straight tunnels without an intersection to get most efficiently to a promising place. In order to do this, they check if given lines intersect. To support independent elaboration, it is important to prepare step by step hints to help students when they get stuck at any stage. Finally, the learners visualize the scene with the help of augmented reality and check their results.

\section{References}

1. Ashcraft, M.H.; Moore, A.M. Mathematics Anxiety and the Affective Drop in Performance. J. Psychoeduc. Assess. 2009, 27, 197-205. [CrossRef]

2. Chang, H.; Beilock, S. The math anxiety-math performance link and its relation to individual and environmental factors: A review of current behavioral and psychophysiological research. Current Opinion in Behavioral Sciences. Neurosci. Educ. 2016, 10, 33-38.

3. Dowker, A.; Sarkar, A.; Looi, C.Y. Mathematics Anxiety: What Have We Learned in 60 Years? Front. Psychol. 2016, 7, 508. [CrossRef] [PubMed]

4. Ellis, J.; Fosdick, B.K.; Rasmussen, C. Women 1.5 Times More Likely to Leave STEM Pipeline after Calculus Compared to Men: Lack of Mathematical Confidence a Potential Culprit. PLoS ONE 2016, 11, 7. [CrossRef] [PubMed]

5. Khan, M.; Trujano, F.; Maes, P. Mathland: Constructionist Mathematical Learning in the Real World Using Immersive Mixed Reality. In Immersive Learning Research Network. Communications in Computer and Information Science; Springer: Berlin/Heidelberg, Germany, 2018; pp. 133-147.

6. Feenan, K. Social Resiliency in Digital Games. In Proceedings of the Immersive Learning Research Network 4th International Conference, iLRN 2018, Missoula, MT, USA, $24-29$ June 2018; Springer: Chan, Switzerland, 2018; pp. 189-197.

7. Prensky, M. Digital Natives, Digital Immigrants. On Horiz. 2001, 9, 1-6.

8. Feierabend, S.; Plankenhorn, T.; Rathgeb, T. JIM-Studie 2016. Jugend, Information, (Multi-) Media; Medienpädagogischer Forschungsverbund Südwest: Stuttgart, Germany, 2016.

9. Azuma, R.T. A survey of augmented reality. Presence Teleoper. Virtual Environ. 1997, 6, 355-385. [CrossRef]

10. Dörner, R.; Jung, B.; Grimm, P.; Broll, W.; Göbel, M. Introduction. In Virtual und Augmented Reality (VR/AR); Springer: Berlin/Heidelberg, Germany, 2013; pp. 1-31.

11. Grimm, P.; Herold, R.; Hummel, J.; Broll, W. VR-Eingabegeräte. In Virtual und Augmented Reality (VR/AR); Springer: Berlin/Heidelberg, Germany, 2013; pp. 97-125.

12. Broll, W. Augmentierte Realität. In Virtual und Augmented Reality (VR/AR); Springer: Berlin/Heidelberg, Germany, 2013; pp. 241-294.

13. Martin-Gutierrez, J.; Mora, C.; Añorbe, B.; González-Marrero, A. Virtual Technologies Trends in Education. Eurasia J. Math. Sci. Technol. Educ. 2017, 13, 469-486. 
14. Wittmann, E. Christian Grundfragen des Mathematikunterrichts, 6th ed.; Vieweg + Teubner Verlag: Wiesbaden, Germany, 1981.

15. Radu, I. Augmented reality in education: A meta-review and cross-media analysis. Pers. Ubiquitous Comput. 2014, 18, 1533-1543. [CrossRef]

16. Morrison, A.; Oulasvirta, A.; Peltonen, P.; Lemmela, S.; Jacucci, G.; Reitmayr, G.; Näsänen, J.; Juustila, A. Like bees around the hive: A comparative study of a mobile augmented reality map. In Proceedings of the SIGCHI Conference on Human Factors in Computing Systems, Boston, MA, USA, 4-9 April 2009; pp. 1889-1898.

17. Kaufmann, H.; Dünser, A. Summary of Usability Evaluations of an Educational Augmented Reality Application. In Virtual Reality; Springer: Berlin/Heidelberg, Germany, 2007; pp. 660-669.

18. Freitas, R.; Campos, P. SMART: A System of Augmented Reality for Teaching 2nd Grade Students. In Proceedings of the 22nd British HCI Group Annual Conference on People and Computers: Culture, Creativity, Interaction, Liverpool, UK; 2008; Volume 2, pp. 27-30.

19. Chen, Y. A study of comparing the use of augmented reality and physical models in chemistry education. In Proceedings of the ACM International Conference on Virtual Reality Continuum and Its Applications, Hong Kong, China; 2006 ; pp. 369-372.

20. Baumgartner, P.; Herber, E. Höhere Lernqualität durch interaktive Medien?-Eine kritische Reflexion. In Erziehung $\mathcal{E}$ Unterricht; Österreichischer Bundesverlag Schulbuch GmbH \& Co. KG: Wien, Österreich, 2013.

21. Fowler, C. Virtual reality and learning: Where is the pedagogy? Br. J. Educ. Technol. 2015, 46, 412-422. [CrossRef]

22. Mikropoulos, T.A.; Natsis, A. Educational virtual environments: A ten-year review of empirical research (1999-2009). Comput. Educ. 2011, 56, 769-780. [CrossRef]

23. Mohler, J.L. Using interactive multimedia technologies to improve student understanding of spatially-dependent engineering concepts. In Proceedings of the GraphiCon, Nizhny, Novgorod, 10-15 September 2001.

24. Thurstone, L.L. Primary Mental Abilities; University of Chicago Press: Chicago, IL, USA, 1938.

25. Dornheim, D. Prädiktion von Rechenleistung und Rechenschwäche: Der Beitrag von Zahlen-Vorwissen und Allgemein-Kognitiven Fähigkeiten; Logos Verlag Berlin GmbH: Berlin, Germany, 2008.

26. Weigand, H.; Filler, A.; Hölzl, R.; Kuntze, S.; Ludwig, M.; Roth, J.; Schmidt-Thieme, B.; Wittmann, G. Didaktik der Geometrie für die Sekundarstufe I; Springer: Berlin/Heidelberg, Germany, 2018.

27. Henn, H.-W.; Filler, A. Analytische Geometrie. In Didaktik der Analytischen Geometrie und Linearen Algebra; Springer: Berlin/Heidelberg, Germany, 2015; pp. 149-238.

28. Kaufmann, H.; Schmalstieg, D.; Wagner, M. Construct3D: A Virtual Reality Application for Mathematics and Geometry Education. Educ. Inf. Technol. 2000, 5, 263-276. [CrossRef]

29. Schnabel, M.A.; Kvan, T. Spatial Understanding in Immersive Virtual Environments. Int. J. Archit. Comput. 2003, 1, 435-448. [CrossRef]

30. Mantovani, F. VR Learning: Potential and Challenges for the Use of 3D Environments in Education and Training; Galimberti, C., Riva, G., Eds.; IOS Press: Amsterdam, The Netherlands, 2001; pp. 207-225.

31. Shin, D.H.; Dunston, P.S.; Wang, X. View changes in augmented reality computer-aided-drawing. ACM Trans. Appl. Percept. TAP 2005, 2, 1-14. [CrossRef]

32. Math-VR App. Available online: https:/ / www.ace-learning.com/app/math-vr (accessed on 11 June 2021).

33. Augmented Maths. Available online: http://www.et.iitb.ac.in/labs/am/index.html (accessed on 11 June 2021).

34. Rebollo, C.; Remolar, I.; Rossano, V.; Lanzilotti, R. Multimedia augmented reality game for learning math. Multimed. Tools Appl. 2021, 1-18. [CrossRef]

35. Radu, I.; McCarthy, B.; Kao, Y. Discovering educational augmented reality math applications by prototyping with elementaryschool teachers. In Proceedings of the 2016 IEEE Virtual Reality (VR), Greenville, SC, USA, 19-23 March 2016; pp. 271-272.

36. Auliya, R.N.; Munasiah, M. Mathematics learning instrument using augmented reality for learning 3D geometry. J. Phys. Conf. Ser. 2019, 1318, 12069. [CrossRef]

37. Cai, S.; Liu, E.; Yang, Y.; Liang, J.C. Tablet-based AR technology: Impacts on students' conceptions and approaches to learning mathematics according to their self-efficacy. Br. J. Educ. Technol. 2019, 50, 248-263. [CrossRef]

38. Geogebra Augmented Reality. Available online: https://www.geogebra.org/m/agpb7bq7 (accessed on 11 June 2021).

39. CleARmaths Website. Available online: https:/ /www.clearmaths.org/en (accessed on 10 May 2021).

40. Zxing. Github. Available online: https://github.com/zxing/zxing (accessed on 10 May 2021).

41. Qrcode.js. Available online: https://davidshimjs.github.io/qrcodejs/ (accessed on 10 May 2021).

42. WordPress. Available online: https:// wordpress.org (accessed on 10 May 2021).

43. Bujak, K.R.; Radu, I.; Catrambone, R.; Macintyre, B.; Zheng, R.; Golubski, G. A psychological perspective on augmented reality in the mathematics classroom. Comput. Educ. 2013, 68, 536-544. [CrossRef] 